\title{
Hydroxylation of recombinant human collagen type I alpha 1 in transgenic maize co-expressed with a recombinant human prolyl 4-hydroxylase
}

Xing Xu' ${ }^{1}$, Qinglei Gan², Richard C Clough ${ }^{3,4}$, Kameshwari M Pappu ${ }^{3,5}$, John A Howard ${ }^{3,6}$, Julio A Baez ${ }^{7,8}$ and Kan Wang 2* $^{*}$

\begin{abstract}
Background: Collagens require the hydroxylation of proline (Pro) residues in their triple-helical domain repeating sequence Xaa-Pro-Gly to function properly as a main structural component of the extracellular matrix in animals at physiologically relevant conditions. The regioselective proline hydroxylation is catalyzed by a specific prolyl 4-hydroxylase (P4H) as a posttranslational processing step.

Results: A recombinant human collagen type I $\alpha-1$ ( $r C l \alpha 1)$ with high percentage of hydroxylated prolines (Hyp) was produced in transgenic maize seeds when co-expressed with both the $\alpha$ - and $\beta$-subunits of a recombinant human $\mathrm{P} 4 \mathrm{H}(\mathrm{rP} 4 \mathrm{H})$. Germ-specific expression of rCla 1 using maize globulin-1 gene promoter resulted in an average yield of $12 \mathrm{mg} / \mathrm{kg}$ seed for the full-length $\mathrm{rCla} 1$ in seeds without co-expression of $\mathrm{rP} 4 \mathrm{H}$ and $4 \mathrm{mg} / \mathrm{kg}$ seed for the rCla $1(\mathrm{rCl}$ 1-OH) in seeds with co-expression of $\mathrm{rP} 4 \mathrm{H}$. High-resolution mass spectrometry (HRMS) analysis revealed that nearly half of the collagenous repeating triplets in $\mathrm{rCl} \alpha 1$ isolated from $\mathrm{rP} 4 \mathrm{H}$ co-expressing maize line had the Pro residues changed to Hyp residues. The HRMS analysis determined the Hyp content of maize-derived rCla 1-OH as $18.11 \%$, which is comparable to the Hyp level of yeast-derived $\mathrm{rCl} \alpha 1-\mathrm{OH}(17.47 \%)$ and the native human Cla1 (14.59\%), respectively. The increased Hyp percentage was correlated with a markedly enhanced thermal stability of maize-derived $\mathrm{rCl}$ 1 1-OH when compared to the non-hydroxylated $\mathrm{rCl}$ l 1 .
\end{abstract}

Conclusions: This work shows that maize has potential to produce adequately modified exogenous proteins with mammalian-like post-translational modifications that may be require for their use as pharmaceutical and industrial products.

\section{Background}

Collagen is the most abundant protein found in animals. It has been used widely for industrial and medical applications such as drug delivery and tissue engineering $[1,2]$. Human type I collagen is the most abundant collagen type in the human body and is also one of the most studied collagen types. It is a heterotrimer composed of two $\alpha 1$ (CI $\alpha 1)$ and one $\alpha 2(\mathrm{CI} \alpha 2)$ chains with the helical region composed by a repeating composition of Xaa-Yaa-Gly, where $\mathrm{X}$ and $\mathrm{Y}$ are typically proline (Pro) and hydroxyproline (Hyp) [3]. Collagens used commercially are traditionally extracted from animal

\footnotetext{
* Correspondence: kanwang@iastate.edu

${ }^{2}$ Department of Agronomy, lowa State University, Ames, IA 50011-1010, USA Full list of author information is available at the end of the article
}

tissues. These products contain different types of collagen and may be contaminated with potential immunogenic and infective agents considered hazardous to human health. Thus, recombinant technology has been developed to produce high quality and animal derived contaminant-free collagens. Recombinant collagens have been produced in mammalian cells [4], insect cell cultures [5], yeast [6], and plant cell culture [2,7].

Transgenic plant systems have advantages over other recombinant production systems in terms of lower cost, higher capacity, lower infective agents/toxins contamination risk, and inexpensive storage capability facilitating processing $[8,9]$. The production of plant derived recombinant collagen I $\alpha-1$ ( $\mathrm{rCI} \alpha 1)$ was reported in 2000 using tobacco [10] and tobacco cell culture [2].
C Biomed Central

C 2011 Xu et al; licensee BioMed Central Ltd. This is an Open Access article distributed under the terms of the Creative Commons Attribution License (http://creativecommons.org/licenses/by/2.0), which permits unrestricted use, distribution, and reproduction in any medium, provided the original work is properly cited. 
The rCI $\alpha 1$ was also expressed in transgenic maize seed $[11,12]$ and barley [13].

A challenge for producing rCI 1 in non-mammalian expression systems such as transgenic plants is the resulting low regioselective hydroxyproline content that makes the product unstable at physiologically relevant temperatures. In humans the 4-hydroxyproline residues synthesized by prolyl 4-hydroxylases ( $\mathrm{P} 4 \mathrm{Hs}$ ) as a posttranslational modification increase the stability of the collagen triple helix structure [14]. The stability of the collagen is increased with the presence of the hydroxyproline primarily through stereoelectronic effects [15]. On the other hand, the hydroxyproline content for the $\mathrm{rCI} \alpha 1$ is almost zero in transgenic tobacco [10], or very low in transgenic maize [11] when $\mathrm{rCI} \alpha 1$ is not coexpressed with $\mathrm{P} 4 \mathrm{H}$. Since the insect, microbial and plant endogenous $\mathrm{P} 4 \mathrm{Hs}$ are not able to achieve the same level of hydroxylation of $\mathrm{rCI} \alpha 1$ as present in the human CI 1 chain, the co-expression with collagen of a recombinant animal $\mathrm{P} 4 \mathrm{H}(\mathrm{rP} 4 \mathrm{H})$ is necessary to increase the hydroxyproline content of the $\mathrm{rCI} \alpha 1$ to deliver a stable product. In tobacco, co-expression of $\mathrm{P} 4 \mathrm{H}$ with an $\alpha$ subunit from $C$. elegans and a $\beta$ subunit from mouse [16] or a recombinant human $\mathrm{P} 4 \mathrm{H}$ [17] led to increased hydroxyproline levels of the rCI $\alpha 1$. Similar results were seen in tobacco cell culture [2]. However, the tobacco-derived collagen still had lower Hyp content compared to native human CI 1 making this product unsuitable for use in many applications.

In this study, we generated transgenic maize lines expressing the human $\mathrm{rCI} \alpha 1$ gene alone or lines coexpressing both $\mathrm{rCI} \alpha 1$ and $\mathrm{rP} 4 \mathrm{H}$ genes. Using highresolution mass spectrometry (HRMS) analysis, we measured the percentages of Hyp and Pro residues in the rCI 1 protein extracted from transgenic maize seeds as well as the actual positions of hydoxylated prolines. We also performed in vitro pepsin treatment at different temperatures to compare the thermal stabilities of maize-derived hydroxylated or non-hydroxylated $\mathrm{rCI} \alpha 1$ proteins. Here, we report for the first time that by co-expressing $\mathrm{rP} 4 \mathrm{H}$ genes, maize can produce $\mathrm{rCI} \alpha 1$ with a hydroxyproline content comparable to native human type I collagen. This achievement provides further confirmation that maize seeds can be used to produce exogenous proteins that require mammalianlike posttranslational modifications for use in specific applications.

\section{Results}

Generation of maize lines expressing $\mathrm{rCl} \alpha 1$ with and without $\mathrm{rP4H}$ co-expression in seeds

The constructs used in this study are shown in Figure 1. The CGB construct carries a gene encoding a recombinant full-length human collagen type I, rCI $\alpha 1$, and the CGD construct carries the rCI 1 gene and both $\alpha$ and $\beta$ subunits of recombinant human prolyl 4-hydroxylase, $\mathrm{rP} 4 \mathrm{H} \alpha$ and $\mathrm{rP} 4 \mathrm{H} \beta$. The $\mathrm{rCI} \alpha 1$ gene was partially maize codon-optimized and its expression was driven by a maize embryo specific globulin-1 promoter (Pglb, [18]). A barley alpha amylase signal sequence (BAASS, [19]) was used as a substitute for the human CI $\alpha 1$ signal peptide (UniProtKB/Swiss-Prot: P02452 [1-22]). The combination of embryo specific promoter and the BAASS has demonstrated high expression of foreign proteins in maize seed [20-22]. The rCI 1 gene lacks the N-propeptide but contains the telopeptide sequences both at the $\mathrm{N}$ and $\mathrm{C}$ terminal regions. A 29 amino acid bacteriophage T4 fibritin foldon peptide sequence [23] was fused at the $\mathrm{C}$-terminus to the $\mathrm{rCI} \alpha 1$ replacing the $\mathrm{C}$-propeptide. The foldon, as the native $\mathrm{C}$-propeptide, facilitates the $\mathrm{rCI} \alpha 1$ triple-helical assembly and enhances its stability [23]. To avoid undesired DNA rearrangement caused by using identical sequences (such as using same promoters for multiple gene expression in a single construct), we chose to use the maize ubiquitin promoter (Pubi, [24]) to drive the expression of $\alpha$ and $\beta$ subunits of $\mathrm{rP} 4 \mathrm{H}$. It was shown previously that there is a preferential accumulation of recombinant protein in germ tissue using the ubiquitin promoter [25].

Both constructs were introduced into maize $\mathrm{Hi}$ II germplasm using immature embryo via an Agrobacterium-based transformation system. Twelve independent

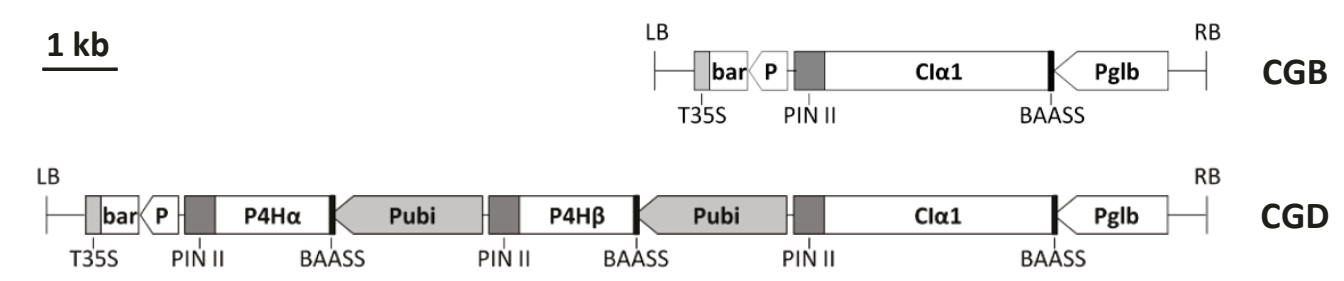

Figure 1 A schematic representation of the two constructs used in this study. LB, left border of Agrobacterium T-DNA; T35S, CaMV 35S terminator; bar, bialaphos resistant coding sequence; P, CaMV 355 promoter; PIN II, potato protease inhibitor II gene terminator; Cla 1, human collagen I $\alpha 1$ chain coding sequence; BAASS, barley alpha amylase signal sequence; P4H $\alpha$, prolyl 4-hydroxylase $\alpha$ subunit; P4H $\beta$, prolyl 4hydroxylase $\beta$ subunit; Pglb, maize globulin-1 promoter; Pubi, maize ubiquitin promoter; RB, right border of Agrobacterium T-DNA. 
transgenic events for CGB and 21 events for CGD, respectively, were recovered and brought to maturity in the greenhouse using pollen donors from an elite inbred. Initial transgene expression screens were conducted on both callus and $\mathrm{T}_{1}$ seeds using an enzymelinked immunosorbent assay (ELISA) to detect the expression of $\mathrm{rCI} \alpha 1$, and $\alpha$ and $\beta$ subunits of $\mathrm{rP} 4 \mathrm{H} . \mathrm{T}_{2}$ seeds from events with the highest transgene expressions were produced by self pollination.

For $\mathrm{T}_{1}$ seed analysis, seeds from multiple plants derived from each event were analysed. In depth molecular and biochemical characterizations of $\mathrm{rCI} \alpha 1$ described in this study were performed on $\mathrm{T}_{2}$ seeds from one selected CGB and CGD event, respectively. Individual seeds of the transgenic events were analyzed by polymerase chain reaction (PCR) to separate transgene positive seeds from negative ones. Positive seeds were pooled and analyzed by ELISA for the expression of the rCI $\alpha 1$. Negative null segregant seeds were used as controls.

The average expression level of $\mathrm{rCI} \alpha 1$ measured by ELISA in event CGB was $1.86 \pm 1.26 \mathrm{mg} / \mathrm{g}$ of total soluble protein (TSP) or $12.14 \pm 8.06 \mathrm{mg} / \mathrm{kg}$ of dry seed weight (DSW). The highest $\mathrm{rCI} \alpha 1$ content measured to date from a single CGB seed was $3.54 \mathrm{mg} / \mathrm{g}$ TSP or $25.11 \mathrm{mg} / \mathrm{kg}$ DSW. The average expression level of the rCI 1 in event CGD was about four times lower than that of in event CGB, which was $0.58 \pm 0.26 \mathrm{mg} / \mathrm{g}$ TSP or $4.40 \pm 2.09 \mathrm{mg} / \mathrm{kg}$ DSW. The highest rCI 1 expression in single CGD seed was $0.92 \mathrm{mg} / \mathrm{g}$ TSP or 7.54 $\mathrm{mg} / \mathrm{kg}$ DSW.

Figure 2 shows the detection of $\mathrm{rCI} \alpha 1$ in the total protein extracts from CGB and CGD seeds. Because of the low expression level of $\mathrm{rCI} \alpha 1$ in CGD seeds, we concentrated the extract using an Amicon Ultra-15 Centrifugal Filter Unit with Ultracel-30 membrane (cat \# UFC903008, Millipore) before loading on the gel. Figure 2 shows that rCI 1 could be detected from both CGB and CGD protein samples using anti-foldon antibody.

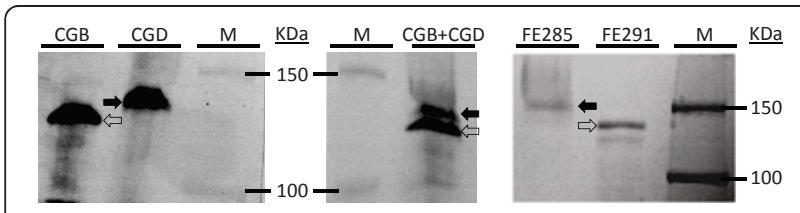

Figure 2 Analysis of electrophoretic mobility difference of rCl $\alpha 1$ in the CGB and CGD line. Equal volumes of total protein extracts from seeds of CGB, CGD $(10 \times$ concentrated by volume) and mixture of $C G B+C G D$ extracts were loaded on the gel. The rCl $\alpha 1$ from CGB and CGD lines were detected by western blot using anti-foldon antibody. Pichia-derived rCl 1 (FE291) and rCla1$\mathrm{OH}$ (FE285) were included as controls and detected by Coomassie Brilliant Blue staining. Open arrows, rCl $\alpha 1$ from CGB or FE291; solid arrows, $\mathrm{OH}-\mathrm{rCl} \alpha 1$ from CGD or FE285. M, molecular weight marker.
No cross-reacting band at a similar position could be detected in non-transgenic maize seeds (data not shown). It was observed that the CGB rCI $\alpha 1$ migrated faster than its CGD counterpart (Figure 2, open arrow in Lane CGB vs solid arrow in Lane CGD), suggesting different electrophoretic mobility for these two proteins. To exclude that the observed protein migration difference was due to lane shifts during electrophoresis, we mixed the TSPs from both CGB and CGD before loading on the gel. Lane CGB+CGD of Figure 2 shows there are two distinct major bands that cross-reacted with anti-foldon antibody. This result indicates that the rCI $\alpha 1$ proteins derived from maize CGB and CGD events have different electrophoretic mobility, with CGD rCI 1 moves slower than CGB rCI 1 . The altered electrophoretic mobility may reflect the increase in molecular weight of $\mathrm{rCI} \alpha 1$ that due partially to increased numbers of hydroxylated proline in $\mathrm{rCI} \alpha 1$ from CGD event, which is also co-expressing the $\mathrm{rP} 4 \mathrm{H}$ genes. The difference in electrophoretic mobility can also been seen in Pichia-derived rCI 1 (Figure 2, FE291) and hydroxylated rCI $\alpha 1$ (Figure 2, FE285).

The expression of the $\beta$ subunit of $\mathrm{rP} 4 \mathrm{H}$ in the CGD seeds was verified by Western Blotting with an anti $\mathrm{P} 4 \mathrm{H} \beta$ monoclonal antibody (Figure 3 ). A main band at $\sim 60 \mathrm{kD}$ (open triangle, Figure 3) was detected in CGD, but not in $C G B$ and non-transgenic wild type maize control, as expected. A weak secondary band detected in CGD is likely due to cross-reactivity of other forms of $\mathrm{rP} 4 \mathrm{H} \beta$ in maize. The detection of $\alpha$ subunit of $\mathrm{P} 4 \mathrm{H}$ was performed in transgenic callus but not in seeds (data not shown).

To determine whether rCI 1 can also be detected in tissues other than seeds, we performed both protein and transcript analyses of rCI 1 in CGB and CGD plants. Maize leaf samples from 5 different development stages were collected. Total RNA and proteins were prepared from these tissues and subjected to Reverse Transcriptase PCR (RT-PCR) and ELISA, respectively. No detectable $\mathrm{rCI} \alpha 1$ transcript and protein could be observed in these samples (data not shown), suggesting that the rCI 1 is not expressed in leaf tissue in both lines as expected.

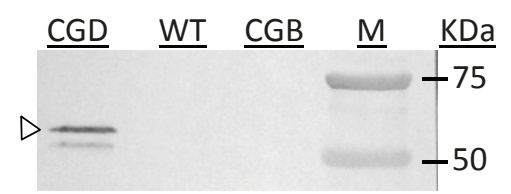

Figure 3 Western blot analysis of the $\mathrm{rP} 4 \mathrm{H} \beta$ using anti-P4H $\beta$ antibody. Equal volume of total protein extraction from seeds of CGB, CGD and non-transgenic control maize (WT) extracts was loaded on the gel. Open triangle, rP4H $\beta$. M: molecular weight marker. 


\section{Co-expression of rP4H increases the hydroxylation of $\mathrm{rCl} \alpha 1$}

To examine the percentage and positions of the prolines that were hydroxylated by the co-expression of $\mathrm{rP} 4 \mathrm{H}$ in the CGD event, we carried out proteomics analysis of gel purified $\mathrm{rCI} \alpha 1$ using liquid chromatography tandem mass spectrometry (LC-MS/MS) on the Linear Ion Trap Orbitrap (LTQ Orbitrap) Mass Spectrometer, a high resolution mass spectrometry (HRMS). The HRMS not only can verify the amino acid sequence of the $\mathrm{rCI} \alpha 1$, but also can identify the positions of hydroxylated proline residues (Hyp). In addition to maize-derived $\mathrm{rCI} \alpha 1$ proteins from CGB and CGD, we also included three control samples: gel isolated CI $\alpha 1$ fragment from human collagen (cat \# 234138, CalBiochem Inc), Pichiaderived rCI 1 (isolated from strain FE291 that does not co-express $\mathrm{rP} 4 \mathrm{H}$ ) and Pichia-derived hydroxylated rCI $\alpha 1$ (isolated from strain FE285 that co-express $\mathrm{rP} 4 \mathrm{H}$ ) (FibroGen).

Results are summarized in Figure 4 and Table 1. The protein sequence coverage by the HRMS (yellow highlighted sequences in Figure 4) on the five samples ranged from $58.66 \%$ (human CI $\alpha 1$ ) to $85.81 \%$ (Pichia CI 1 $\mathrm{OH})$. To compare the percentages and positions of Hyp in each sample, we chose the peptide regions in all five CI 1 proteins (475 AA) that were covered by the HRMS (red boxes in Figure 4). The common peptide regions represent $44.94 \%$ of the full-length CI $\alpha 1$ sequence (1057 AA). A total of 114 Pro and Hyp out of 475 total amino acids $(24.00 \%)$ were identified by the HRMS in all samples (Figure 4).

For two maize-derived CI $\alpha 1$ samples, a total of 28 and 86 Hyp were identified from CGB and CGD (green highlighted amino acids in Figure 4), respectively, representing a Hyp percentage of $5.89 \%$ and $18.11 \%$, respectively, for these two lines (Table 1). This result indicates that the co-expression of $\mathrm{rP} 4 \mathrm{H}$ in maize can greatly enhance the hydroxylation of prolines on collagen molecules. The increased number of Hyp in rCI 1 from CGD samples may partially contributed to the increased molecular weight and thereby decreased the migration rate (Figure 2).

Because rP4H catalyzes hydroxylation of Pro residues in the Yaa position of the Xaa-Yaa-Gly triplets within collagen strands [26], we further compared the Pro residues on all Xaa-Pro-Gly triplets in both maize CGB and CGD lines. HRMS analysis identified 752 AA (71.14\%) from maize-rCI 1 (CGB) and 818 AA (77.39\%) from maize $\mathrm{rCI} \alpha 1-\mathrm{OH}$ (CGD) as shown in Table 1 and Figure 4 (bold and yellow highlighted letters). Among these HRMS identified AA, we chose 652 AA that were shared for both CGB and CGD. We further identified a total of 90 sets of collagenous triplets within the 652 AA. Among the 90 sets of triplets, 44 sets (48.9\%) have the Pro residues changed to Hyp (double underlined triplets in Figure 4) in both CGB and CGD lines; 5 sets (5.6\%) have the Pro unchanged (single underlined triplets in Figure 4) in both lines. On the other hand, 41 sets of triplets $(45.6 \%)$ have the Pro residues changed to Hyp (black boxes in Figure 4) only in $\mathrm{rCI} \alpha 1$ isolated from CGD, indicating that nearly half of the collagenous triplets were posttranslationally modified by the coexpression of $\mathrm{rP} 4 \mathrm{H}$ genes in CGD maize line.

Seventy-one Hyp residues out of 475 AA by HRMS (14.95\%) were identified in human CI 1 control sample (Table 1). For Pichia samples, while only two Hyp residues $(0.42 \%)$ were found in non-hydroxylated CI $\alpha 1$ (FE291), 83 Hyp residues (17.47\%) were found in hydroxylated CI $\alpha 1$ (FE285), indicating that the co-expression of $\mathrm{P} 4 \mathrm{H}$ in Pichia had also dramatically increased proline hydroxylation in collagen (Table 1).

\section{Co-expression of rP4H enhances the thermal stability of $\mathrm{rCl} \alpha 1$}

To further characterize the maize-derived $\mathrm{rCI} \alpha 1$ and rCI $\alpha 1-\mathrm{OH}$, we carried out thermal stability analysis using pepsin digestion at $10^{\circ} \mathrm{C}$ for 15 minutes after heat treatment of protein samples at $4^{\circ} \mathrm{C}$ or temperatures ranged from 29 to $38.6^{\circ} \mathrm{C}$ for 6 minutes. The proteolytic resistance of maize-derived collagens were compared with that of the native human collagen and the recombinant collagen from Pichia pastoris. Figure 5A is a Western Blot results showing the proteolytic resistance of the collagens after $4^{\circ} \mathrm{C}$ heat treatment using anti-foldon antibody. Both non-hydroxylated $\mathrm{rCI} \alpha 1$ from maize (CGB) and non-hydroxylated rCI 1 from Pichia (FE291) were not detected after pepsin treatment. By contrast, the hydroxylated $\mathrm{rCI} \alpha 1$ could be detected from both maize (CGD) and hydroxylated-CI $\alpha 1$ Pichia (FE285) samples, suggesting that the pepsin digestion resistance of these collagens was associated with the higher percentage of Hyp residues.

The thermal stability of $\mathrm{rCI} \alpha 1$ was further characterized by the determination of melting temperature (Tm) using Western analysis. Two different antibodies, antifoldon and anti-25 kD collagen, were used. In our hands, anti-foldon antibody gave results with less nonspecific cross-reactive background bands, while anti-25 $\mathrm{kD}$ antibody appeared to be more sensitive. Because the native human CI $\alpha 1$ can only be detected with anti-25 $\mathrm{kD}$ antibody, we used both antibodies in this study. In the experiments shown in Figure 5B, maize seeds TSP from CGB and CGD were extracted and concentrated as described above. The quantities of maize-derived rCI $\alpha 1$ were estimated by ELISA. Approximately 50-100 $\mathrm{ng} /$ reaction of rCI $\alpha 1$ from CGB and CGD were used for pepsin treatment. As a control, commercial human collagen $(2 \mu \mathrm{g} /$ reaction $)$ was spiked into TSP extracted 
QLSYGYDEK STGGISVP GPMGP SGPR FLP GPP GAP GP QGFQGP P GEP GEPGASGPMGP RGPP GP P GKNGDDGEAGKP GRP GERGPP GPQGARGLPGTAGI Maize $\mathrm{rCI} \alpha 1-\mathrm{OH}$

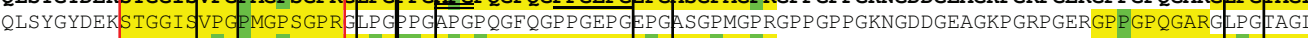
QLSYGYDEKSTGGI SVPGPMGPSGPR LPGPPGAPGPQGFQGPPGEPGEPGASGPMGPRGPPGPPGKNGDDGEAGKPGRPGERGPPGPQGARGLPG IAGI QLSYGYDEKSTGGISVP GPMGP SGPR GLP GP P GAP GP QGF QGP P GEPGEPGASGPMGP RGP P GP P GKNGDDGEAGKPGRPGERGP PGPQGARGLPGTAGL

Pichia $r C I \alpha 1$ Maize $r C I \alpha 1$ Human $C I \alpha 1$

Maize $\mathrm{rCI} \alpha 1-\mathrm{OH}$

Pichia $\mathrm{rCI} \alpha 1-\mathrm{OH}$

Pichia rCI $\alpha I$ Maize $r C I \alpha 1$ Human CI $\alpha 1$ Maize rCI $1-\mathrm{OH}$ Pichia rCI $\alpha 1-\mathrm{OH}$

Pichia rCIa 1 Maize $r C I \alpha 1$ Human CI $\alpha 1$ Maize rCI $\alpha 1-\mathrm{OH}$ Pichia $\mathrm{rCI} \alpha 1-\mathrm{OH}$

Pichia rCI $\alpha 1$ Maize $r C I \alpha$ Human $\mathrm{CI} \alpha 1$ Maize $\mathrm{rCI} \alpha 1-\mathrm{OH}$ Pichia $\mathrm{rCI} \alpha 1-\mathrm{OH}$

Pichia rCI $\alpha 1$ Maize rCI 1 Maize rCIaI Maize rCI $\alpha 1-\mathrm{OH}$ Pichia rCI $1-\mathrm{OH}$

Pichia rCI $\alpha 1$ Maize $r C I \alpha 1$ Human $\mathrm{CI} \alpha I$ Maize rCI $1-\mathrm{OH}$ Pichia rCI $1-\mathrm{OH}$

Pichia rCI 1 Maize rCI $\alpha 1$ Human CI $\alpha 1$ Maize rCI $1-\mathrm{OH}$ Pichia rCI $\alpha 1-\mathrm{OH}$

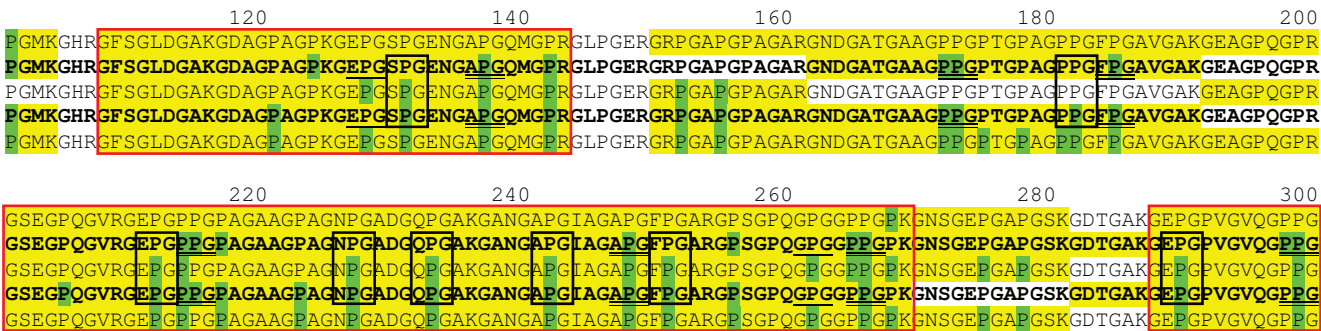
320 340 360 PAGEEGKR FARGEP GP TGLPGPP GERGGP GSR GFP GADGVAGP K GP AGERGSP GP A GP K GSP GEAGRP GEAGLP GAKGLTGSP GSP GP D GK FGP P GP A GQ

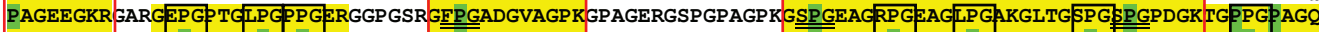

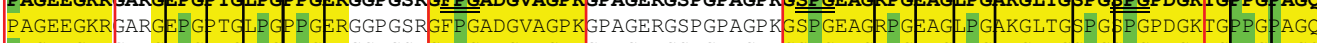

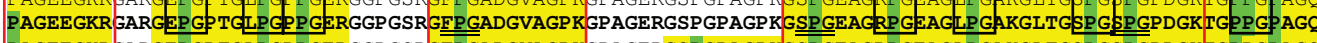
PAGEEGKR FARGEPGP TGLPGP PERGGP GSR GEPGADGVAGP KGPAGERGSPGPAGP KG GPGEAGRPGEAGLPGAKGLTGSPGSPGPDGK IFPPGPAGQ

420 440 460 480 500 DGRP GPP GP P GAR GQAGVMGFP GP K GAAGEP GKAGER GVP GPP GAVGPAGKDGEAGAOGP P GPAGPAGER EEQGPAGSP GF QGLPGPAGPP GEAGKP GEQ DGRPGPPGPPGARGQAGVMGFPGPKGAAGEPGKAGER GVPGPPGAVGPAGKDGEAGAQGPPGPAGPAGER GEQGPAGSPGFQGLPGPAGPPGEAGKPGEO

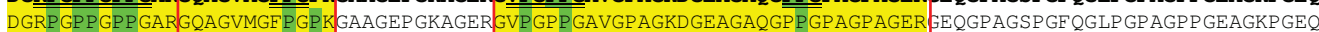

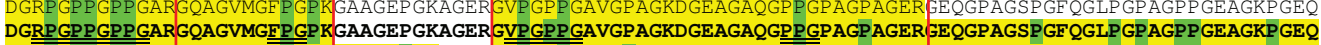

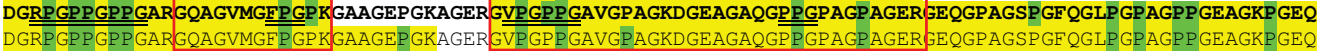

GVP GDLGAP GP SGARGERGFP GER GVOGPP GPAGPRGANGAP GND GAKGDAGAP GAP GSOGAP GLOGMP GER GAAGLPGPKGDRGDAGPKGADGSP GKDC GVPGDLGAPGP SGARGERGFPGERGVQGPPGPAGPR GANGAPGNDGAKGDAGAPGAPGSQGAPGLQGMPGERGAAGLPGKGDRGDAGPKGADGSPGKDG

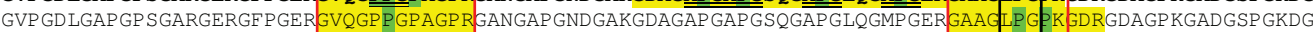
GVPGDLGAPGP SGARGERGFPGERGVQGPPGPAGPRGANGAP GNDGAKGDAGAPGAPGSQGAPGLQGMPGER GAAGPG KGDRGDAGPKGADGSPGKDG GVPGDLGAPGP SGARGERGEPGERGVQGP GPAGPR GANGAP GND GAKGDAGAPGAPGSQGAPGLQGMPG ER GAAGLPGPKGDRGDAGPKGADGSPGKDG

620 640

RR GLTGP I GPP GPAGAPGDKGESGPSGPAGPTGARGAPGDRGEPGPPGPAGFAGPP GADGQPGAKGEP GDAGAKGDAGPP GPAGPAGPP GP IGNVGAPGA VRGLTGP IGPPGPAGAPGDKGESGP SGPAGPTGARGAPGPREPGPGPAGFAGPPGADGPPGAKG EPGPAGAKGDAGPPGPAGPAGPPGPIGNVGAPGA

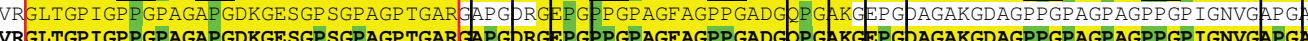
VRGLTGPIGPPGPAGAPGDKGESGP SGPAGPTGARGAPGPRGPGPPGPAGF AGPPGADGDPGAKGEPGAGAKGDAGPPGPAGPAGPPGPIGNVGAPG

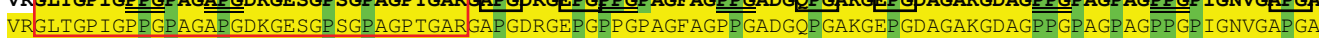

720

740 760 780 KGAR GSAGPP GATGFP GAAGRVGPP GP S GNAGP P GPP GPAGKEGGKGP RGETGPAGRP GEVGPP GPP GPAGEK GSP GADGPAGAPGTPGPQGIAGQRGVV KGAR GSAGPGATGFPGAAGRVGPPGP SGNAGPPGPPGPAGKEGGKGPRGETGPAGRFEVGPPGPPGPAGEKGSPGADGPAGAPGTPGPQGIAGQRGVV

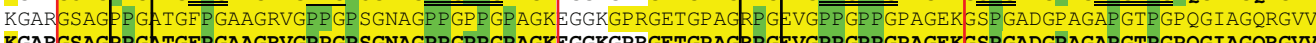
KGARGSAGPPGATGFPGAAGRVGPGP SGNAGPPGPPGPAGKEGGKGPRGETGPAGRPGVGPPGPPGPAGEKGSPGADGPAGAPGTPGPQGIAGQRGVV KGARGSAGPPGATGFPGAAGRVGPPGP SGNAGPPGPPGPAGK:GGKGPRGETGPAGRPGEVGPPGPP GPAGEKG SPGADGPAGAPGTPGPQGIAGQRGVV

820

840

860

880

Pichia $r C I \alpha I$

Maize $r C I \alpha 1$

Human CI $\alpha 1$

Maize $\mathrm{rCI} \alpha 1-\mathrm{OH}$

Pichia rCI $\alpha 1-\mathrm{OH}$

Pichia rCI $\alpha 1$

Maize rCI $\alpha 1$

Human CI $\alpha 1$

Maize $\mathrm{rCI} \alpha 1-\mathrm{OH}$

Pichia $\mathrm{rCI} \alpha 1-\mathrm{OH}$

Pichia $r C I \alpha I$

Maize $r C I \alpha 1$

Human CI 1

Maize $\mathrm{rCI} \alpha 1-\mathrm{OH}$

Pichia $\mathrm{rCI} \alpha 1-\mathrm{OH}$

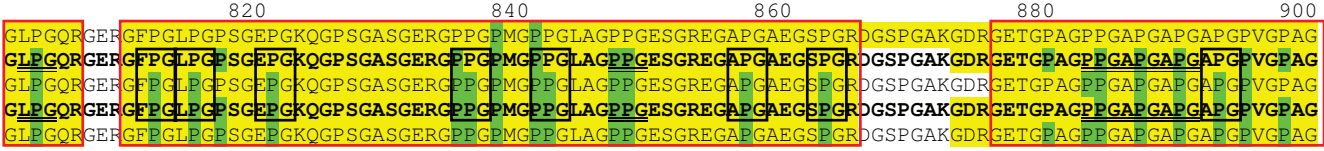

920

940

960

980

R 3 GDRGETGPAGPAGPVGP AGAR GPAGPQGPRGDKGETGEQGDRGIKGHRGE SGLQGP P GP PGSP GEQGP SGASGPAGP R GPP GSAGAP GKDGLNGLP GP SGDRGETGPAGPAGPVGPAGAR GPAGPQGPRGDKGETGEQGDRGIKGHRGF SGLQGPGPGSPGQGP SGASGPAGPR FPGSAGAPGKDGLNGLPGP

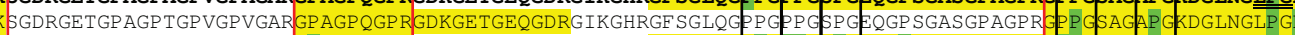
SGDRGETGPAGPAGPVGPAGAR GPAGPQGPR GDKGETGEQGDRGIKGHRGF SGLQGPGPPGSPGEGP SGASGPAGPR EPGSAGAPGKDGLNGLPG

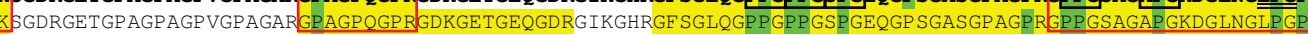

$$
1020
$$

IGPPGPRGRTGDAGPVGP P GP PGPP GP PGPPSAGE DF SF LPQPPQEKAHDGGRYYRA

IGPPGPRGRTGDAGPVGPPGPPGPPGPPGPPSAGFDF SFLPQPPQEKAHDGGRYYRA

IGPPGPR GRTGDAGPVGPP GPPGPP GP P GPP SAGFDF SE LPQPPQEKAHDGGRYYRA

GPPGPR GRTGDAGPVGPPGP PGPPGPPGPP SAGFDF SFLPQPPQEKAHDGGRYYRA

I GPPGP R GRT GDAGPVGP P GP P GP P GP P GPP SAGFDF SE LPQP PQEKAHDGGRYYRA

Figure 4 LC-MS/MS analysis of the rCl $\mathbf{1}$. Full length peptide sequences of 1057 amino acid are listed. Pichia rCla 1, Pichia-derived rCla 1 from strain FE291; Maize rCla 1, maize-derived rCla 1 from line CGB; Human Cla1, gel-isolated Cla 1 fragment from commercial collagen (CalBiochem Inc); Maize rCl 1 1-OH, maize-derived $\mathrm{rCl} \alpha 1$ from line CGD; Pichia $\mathrm{rCl}$ 1-OH, Pichia-derived $\mathrm{rCl} \alpha 1$ from strain FE285. Yellow-highlighted letters: amino acid sequences identified by the Orbitrap; green-highlighted letters: Hyp residues identified by the Orbitrap; red boxes: peptide regions identified in all five samples by the Orbitrap. Black boxes: collagenous triplets Xaa-Pro-Gly with Pro changed to Hyp in Maize rCla1-OH but not in Maize rCla 1; single underlines: triplets with Pro unchanged in both maize lines; double underlines: triplets with Pro changed to Hyp in both maize lines. 
Table 1 Summary of HRMS analysis on five Cl $\alpha 1$ (1057 AA ${ }^{1}$ ) samples from maize, Pichia and human

\begin{tabular}{|c|c|c|c|c|c|}
\hline & $\begin{array}{c}\text { Pichia } \\
\text { Clo1 (FE291) }\end{array}$ & $\begin{array}{c}\text { Maize } \\
\text { Cl } \alpha 1 \text { (CGB) }\end{array}$ & $\begin{array}{l}\text { Human } \\
\text { Cl } \alpha 1\end{array}$ & $\begin{array}{c}\text { Maize } \\
\text { Cl } \alpha 1-\mathrm{OH} \text { (CGD) }\end{array}$ & $\begin{array}{c}\text { Pichia } \\
\text { Cl } \alpha 1-\mathrm{OH} \text { (FE285) }\end{array}$ \\
\hline \multicolumn{6}{|c|}{ Peptides identified by HRMS (highlighted in yellow, Figure 4) } \\
\hline Total \# AA & 680 & 752 & 620 & 818 & 907 \\
\hline Percent HRMS coverage & $64.33 \%$ & $71.14 \%$ & $58.66 \%$ & $77.39 \%$ & $85.81 \%$ \\
\hline \multicolumn{6}{|c|}{ Peptide regions identified in all five $C 1 \alpha 1$ (475 AA) by HRMS (red boxes, Figure 4) } \\
\hline Total \# HYP identified by HRMS, in green & 2 & 28 & 71 & 86 & 83 \\
\hline Percent HYP identified by HRMS & $0.42 \%$ & $5.89 \%$ & $14.95 \%$ & $18.11 \%$ & $17.47 \%$ \\
\hline \% HYP (by AA analysis) & N/A & $1.23 \%^{2}$ & $10.8 \%^{3}$ & $\mathrm{~N} / \mathrm{A}$ & $11.54 \%^{2}$ \\
\hline
\end{tabular}

${ }^{1}$ sequences presents in all five samples

${ }^{2}$ from reference [11]

${ }^{3}$ from reference [28]

from non-transgenic maize seed for pepsin treatment. As can be seen in Figure 5B, both maize-derived $\mathrm{rCI} \alpha 1$ (CGB) and rCIa1-OH (CGD) were as stable as the human collagen control at all temperatures tested in the absence of pepsin. When digested with pepsin, the maize-derived non-hydroxylated $\mathrm{rCI} \alpha 1$ (CGB) was degraded after the heat treatment at temperatures as low as $4^{\circ} \mathrm{C}$. On the other hand, the hydroxylated rCIa1$\mathrm{OH}$ (CGD) could still be detected after temperature treatment as high as $35^{\circ} \mathrm{C}$ when using anti-foldon antibody, and $38.6^{\circ} \mathrm{C}$ when using anti- $25 \mathrm{kD}$ antibody. The difference in Tm results was likely due to the sensitivity and epitope recognition sites of two types of antibodies. Interestingly, the control native human collagen could only withstand the digestion upto temperature treatment around $31^{\circ} \mathrm{C}$. This observation is in fact in agreement with the HRMS analysis of the collagens described in Table 1 and Figure 4. Because the maize-derived rCI 1 1$\mathrm{OH}$ has higher Hyp percentage (18.11\%) than that from human collagen control (14.95\%), it is expected that the increased Hyp residues could help to increase the thermal stability of the collagen molecules.

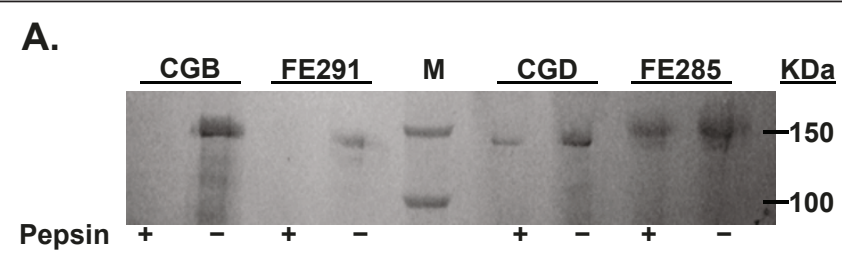

B.

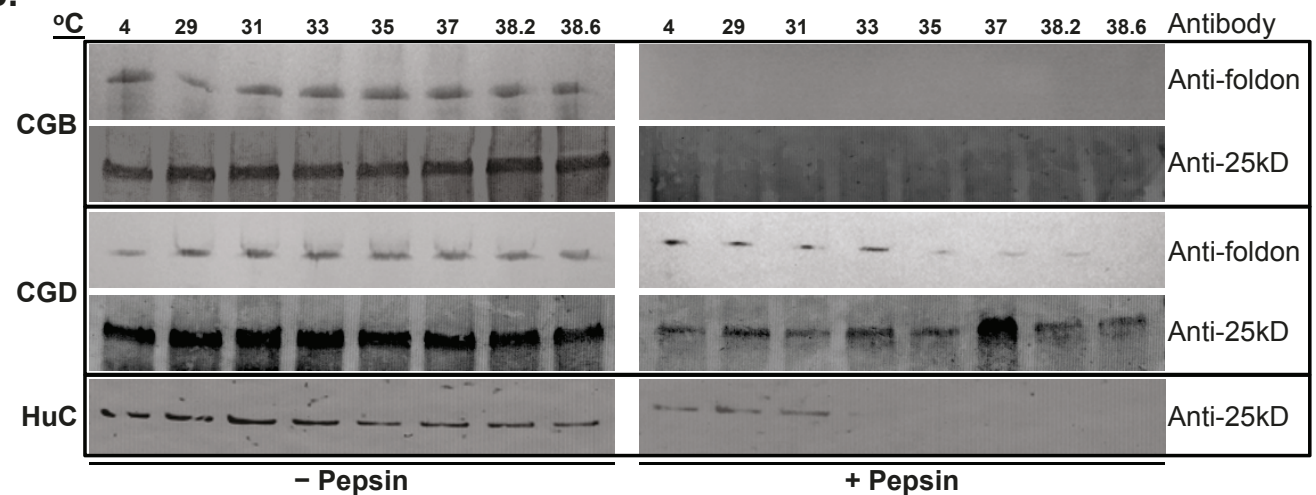

Figure 5 Thermal stability analysis of the $\mathrm{rCl} \alpha 1$ from maize, Pichia and human. (A) Western blot results of the maize-derived $\mathrm{rCl} / \alpha 1$ (CGB), rCla1-OH (CGD), Pichia-derived rCla 1 (FE291), and rCla1-OH (FE285) after $4^{\circ} \mathrm{C}$ incubation and pepsin treatment, using anti-foldon antibody. (B) Western blot results of the maize-derived $\mathrm{rCl} / \mathrm{1}$ (CGB), $\mathrm{rCl}$ 1-OH (CGD), and human $\mathrm{Cl} \alpha 1$ (HuC) after heat treatments under various temperatures and pepsin treatments as indicated, using both anti-foldon and anti-25 kD collagen antibody. M: molecular weight marker. 
Table 2 Summary of plant derived recombinant human collagen I $\alpha 1$

\begin{tabular}{|c|c|c|c|c|c|c|}
\hline \multirow{2}{*}{$\begin{array}{l}\text { Expression } \\
\text { system }\end{array}$} & \multicolumn{3}{|c|}{ Collagen } & \multirow[t]{2}{*}{ rP4H } & \multirow{2}{*}{$\begin{array}{l}\text { Hydroxylation } \\
\text { content }(\%)\end{array}$} & \multirow[t]{2}{*}{ Reference } \\
\hline & Regulatory sequences & Gene & Yield & & & \\
\hline $\begin{array}{c}\text { Tobacco } \\
\text { Leaf }\end{array}$ & P35S (constitutive) + PR-protein SP & $\begin{array}{c}\operatorname{pro\alpha 1(I)} \\
\Delta \operatorname{Npro\alpha 1(I)}\end{array}$ & $\begin{array}{l}30 \mathrm{mg} / \mathrm{kg} \text { powdered } \\
\text { plants }\end{array}$ & $N / A$ & 0.53 & 10 \\
\hline $\begin{array}{c}\text { Tobacco } \\
\text { Leaf }\end{array}$ & P35S (constitutive) + PR-protein SP & $\Delta$ Nproa 1(I) & N/A & N/A & N/A & 27 \\
\hline $\begin{array}{l}\text { Tobacco } \\
\text { Leaf }\end{array}$ & L3 + PR-protein SP & $\Delta$ Nproa 1(I) & $\begin{array}{c}0.5-1 \mathrm{mg} / \mathrm{kg} \text { leaf } \\
\text { material }\end{array}$ & $\begin{array}{c}\text { P1287 + Native SP + } \\
\text { C. elegans } \\
\text { P4Ho/Mouse P4H } \beta\end{array}$ & 8.41 & 16 \\
\hline Tobacco & $\begin{array}{c}\text { rbcS1 (constitutive) + vacuole or apoplast } \\
\text { targeting SPs }\end{array}$ & $\begin{array}{l}\operatorname{pro\alpha 1}(\mathrm{I}) / \\
\operatorname{pro\alpha 2}(\mathrm{I})\end{array}$ & $\begin{array}{l}200 \mathrm{mg} / \mathrm{kg} \text { fresh } \\
\text { leaves }\end{array}$ & $\begin{array}{c}\text { P35S (constitutive) + } \\
\text { vacuole } \\
\text { or apoplast targeting } \\
\text { SPs }+ \\
\text { Human P4H } \alpha / \beta\end{array}$ & 7.55 & 17 \\
\hline $\begin{array}{l}\text { Barley P1 } \\
\text { cell }\end{array}$ & $\begin{array}{c}\text { Ubi (constitutive) }+ \text { At chitinase SP + } \\
\text { HDEL (ER retention) }\end{array}$ & proal(I) & 2-9 $\mu \mathrm{g} / \mathrm{L}$ cell culture & N/A & N/A & 7 \\
\hline Barley Seed & $\begin{array}{c}\text { GluB1 (endosperm specific) + } \\
\text { At chitinase SP + HDEL } \\
\text { (ER retention) }\end{array}$ & Cla 145 kD & $\begin{array}{c}\text { Below detectable } \\
\text { level (Cla } 1) \\
45 \mathrm{mg} / \mathrm{kg} \mathrm{seed} \\
(45 \mathrm{kD})\end{array}$ & $\mathrm{N} / \mathrm{A}$ & $\begin{array}{l}\text { N/A (Clo 1) } 2.8 \\
\quad(45 \mathrm{kD})\end{array}$ & 13 \\
\hline Maize Seed & $\begin{array}{l}\text { globulin-1 (embryo specific) + } \\
\text { barley } \alpha \text {-amylase SP }\end{array}$ & $44 \mathrm{kD}$ & $20 \mathrm{mg} / \mathrm{kg}$ seed & N/A & 2.01 & 29 \\
\hline Maize Seed & $\begin{array}{c}\text { globulin-1 (embryo specific) }+ \\
\text { barley } \alpha \text {-amylase SP }\end{array}$ & Cla 1 & $3 \mathrm{mg} / \mathrm{kg}$ seed & N/A & 1.23 & 11 \\
\hline Maize Seed & $\begin{array}{c}\text { globulin-1 (embryo specific) }+ \\
\text { barley } \alpha \text {-amylase SP }\end{array}$ & Cla 144 kD & $\begin{array}{c}15.9 \mathrm{mg} / \mathrm{kg} \text { germ } \\
(\mathrm{Cl \alpha} 1) \\
49.6 \mathrm{mg} / \mathrm{kg} \text { germ } \\
(44 \mathrm{kD})\end{array}$ & N/A & N/A & 12 \\
\hline Maize Seed & $\begin{array}{l}\text { globulin-1 (embryo specific) + } \\
\text { barley } \alpha \text {-amylase SP }\end{array}$ & $C l \alpha 1$ & $\begin{array}{c}12 \mathrm{mg} / \mathrm{kg} \text { seed } \\
(\mathrm{Cl} \alpha 1) \\
4 \mathrm{mg} / \mathrm{kg} \text { seed } \\
(\mathrm{Cl} 1-\mathrm{OH})\end{array}$ & $\begin{array}{c}\text { Pubi (constitutive) }+ \\
\text { Barley } \\
\alpha \text {-amylase SP }+ \\
\text { Human P4H } / \beta\end{array}$ & 18.11 & This study \\
\hline
\end{tabular}

proa 1(I): human type I procollagen $\alpha 1$ chain

$\Delta$ Npro $\alpha 1(\mathrm{I})$ : human type I procollagen $\alpha 1$ chain lacking $\mathrm{N}$-propeptide

$\Delta \mathrm{NCpro \alpha} 1$ (I): human type I procollagen $\alpha 1$ chain lacking $\mathrm{N}$-propeptide and $\mathrm{C}$-propeptide

Clo 1: sequence information is not clear

$44 \mathrm{kD}: 44 \mathrm{kD}$ fragment of Cla1

$45 \mathrm{kD}: 45 \mathrm{kD}$ fragment of Cl $\alpha 1$

\section{Discussion}

The production of plant-derived recombinant collagens have been reported in tobacco leaves, barley cell culture and seeds, as well as maize seeds as summarized in Table 2. Previous tobacco-derived rCI $\alpha 1$ studies showed that different combinations of recombinant human collagens (i.e. $\mathrm{rCI} \alpha 1, \mathrm{rCI} \alpha 2$, and $\mathrm{N}$-propeptide free $\mathrm{rCI} \alpha 1$ ) were used to improve the production of homotrimeric or heterotrimeric recombinant human type I collagen $[10,16,17,27]$. In a recent paper, Stein et al [17] achieved a high expression level of $200 \mathrm{mg} / \mathrm{kg}$ fresh leaves by expressing the collagens under a Chrysanthemum rbcS1 promoter and vacuolar-targeting signal sequence. Early work with tobacco-derived collagens had very low levels of Hyp $(0.53 \%,[10])$. With co-expression of C. elegans $\mathrm{P} 4 \mathrm{H} \alpha /$ Mouse $\mathrm{P} 4 \mathrm{H} \beta$ [16] or the human $\mathrm{rP} 4 \mathrm{H} \alpha / \beta$ [17], Hyp levels were increased to $8.41 \%$ and $7.55 \%$, respectively. However, this enhanced Hyp level in tobacco is still lower than that of native human collagen CI 1 , which is reported as $10.8 \%$ by amino acid analysis [28] or around $15 \%$ by the HRMS analysis (this work).

Both the full length and a smaller fragment $(45 \mathrm{kD})$ of rCI 1 were produced in barley cell culture [7] and barley seeds [13]. The barley-derived $45 \mathrm{kD}$ collagen has $2.8 \%$ of Hyp content when produced in seeds without co-expression of $\mathrm{rP} 4 \mathrm{H}$ genes [13].

Previous work on fractionation, purification and characterization of maize-derived full length and a smaller fragment $(44 \mathrm{kD})$ of collagen suggested that an accumulation level of about $3 \mathrm{mg} / \mathrm{kg}$ (for the full length) and of $20 \mathrm{mg} / \mathrm{kg}$ (for the $44 \mathrm{kD}$ ) of DSW, respectively $[11,29]$. A similar maize line accumulating the full length $\mathrm{rCI} \alpha 1$ producing maize line (CGB) was used in this study. In our case, the collagen yield of the $\mathrm{rCI} \alpha 1$ accumulating line without $\mathrm{P} 4 \mathrm{H}$ co-expression averages $12 \mathrm{mg} / \mathrm{kg}$ DSW, while the rCI 1 accumulating line with $\mathrm{P} 4 \mathrm{H} \mathrm{co-}$ 
expression (CGD) is about $4 \mathrm{mg} / \mathrm{kg}$. The Hyp percentage in $\mathrm{rCI} \alpha 1$ protein of $\mathrm{CGB}$ was reported as $1.23 \%$ using total amino acid composition (AAC) analysis [11]; however, it was measured at $5.89 \%$ by using HRMS analysis in our study. Similarly, the Hyp percentage in human CI 1 was reported as $10.8 \%$ using AAC analysis [28]. In our HRMS analysis, the Hyp for human CI 1 measured around 15\%. It is not clear why Hyp percentages of CI $\alpha 1$ proteins measured uniformly higher in HRMS analysis than that of in AAC analysis. This discrepancy is likely due to the different degrees of resolution of these two very different methodologies. Because the concentrations of $\mathrm{rCI} \alpha 1$ and $\mathrm{rCI} \alpha 1-\mathrm{OH}$ obtained from maize seeds were too low to be measured by AAC analysis in our study, we were not able to obtain AAC analysis results for comparison.

$\mathrm{P} 4 \mathrm{H}$ is an enzyme that regioselectively modifies the Pro residues in collagenous triplets Xaa-Pro-Gly [30,31] in the ER as a posttranslational modification. Compared to the Pichia recombinant protein production system, maize can produce hydroxylated $\mathrm{rCI} \alpha 1$ with a comparable Hyp percentage (Table 1, 18.11\% in maize CGD vs $17.47 \%$ in Pichia FE285). Interestingly, rCI $\alpha 1$ produced in maize seems to have a higher base-level Hyp percentage when compared to $\mathrm{rCl} \alpha 1$ isolated from Pichia with no $\mathrm{rP} 4 \mathrm{H}$ co-expression (Table $1,5.89 \%$ in maize CGB vs $0.42 \%$ in Pichia FE291). Small numbers of proline at both Xaa and Yaa positions got hydroxylated in CGB maize line without the co-expression of $\mathrm{P} 4 \mathrm{H}$ (data not shown). It is likely that the $\mathrm{rCI} \alpha 1$ produced in maize is also a substrate for plant endogenous $\mathrm{P} 4 \mathrm{Hs}$ with lower efficiency [30].

Conversely, the expression of human $\mathrm{rP} 4 \mathrm{H}$ in maize may also catalyze hydroxylation of Pro residues in any plant endogenous proteins with collagenous domains. We checked amino acid sequences of three abundant seed storage proteins ( $19 \mathrm{kD}$ and $22 \mathrm{kD} \alpha$-zein, and 27 $\mathrm{kD} \gamma$-zein) in maize and did not find any collagenous triplets (X. Xu, unpublished). Therefore we do not expect any Pro to Hyp modifications on these seed storage protein in the $\mathrm{rP} 4 \mathrm{H}$ expressing CGD line. In fact, the Hyp-only AAC analysis on both CGB and CGD seeds showed no differences in Hyp contents ( $\mathrm{X}$. Xu, unpublished). However, because both $\alpha$ and $\beta$ subunits of $\mathrm{rP} 4 \mathrm{H}$ were under the control of the constitutive ubiquitin promoter, it is possible that any of the collagenous triplet domains on proteins in plant cells can be modified by $\mathrm{rP} 4 \mathrm{H}$ in such transgenic lines. It may be desirable in the future to restrict $\mathrm{rP} 4 \mathrm{H}$ expression to seed tissue only using seed specific promoters.

Using HRMS to analyze posttranslational modification has obvious advantages such as low protein quantity requirement, free of contaminating proteins in samples and reading accuracy. However, it does not give $100 \%$ coverage. In this study the peptide coverage ranged from $58.66 \%$ to $85.81 \%$.

Because posttranslational modification is a continuous process in the cells, the collagen isolated from the seeds represents a population of protein molecules, i.e., the proline hydroxylation may vary from one collagen molecule to another. In fact, we have performed multiple HRMS measurements on samples extracted from same batch of seeds. We found that while positions of Pro to Hyp modification may vary between measurements, the overall Hyp content remained constant between these samples.

The thermal stability tests in this report showed that maize-derived $\mathrm{rCI} \alpha 1-\mathrm{OH}$ could still be detected after pepsin digestion followed by heat treatment as high as $35^{\circ} \mathrm{C}$ (using anti-foldon antibody) and $38.6^{\circ} \mathrm{C}$ (using anti-25 kD antibody). Commercial human collagen control undergoing the same treatment could only withstand up to $31^{\circ} \mathrm{C}$ temperatures. Stein et al [17] reported that the melting temperatures for their tobacco-derived collagen heterotrimer and human skin collagen samples were around $39^{\circ} \mathrm{C}$. High melting temperature of plantderived collagen could potentially be useful for certain industrial application where higher melting temperature is desired, for example, biomaterials for tissue engineering [32,33].

We recovered the maize-derived $\mathrm{rCI} \alpha 1$ from the seed total soluble proteins using a previously described protocol [11]. Because collagens are acid soluble proteins, the extraction buffer used had a $\mathrm{pH}$ of 1.7. Unlike Zhang et al. [11], we did not perform extensive purification for rCI $\alpha 1$ before gel electrophoresis and Western blot analysis. When treating such acidic $\mathrm{rCI} \alpha 1$ solutions under high temperature as we normally do before loading protein gels, we were unable to detect them in Western blot, suggesting that the combination of acidic buffer and high temperature could be detrimental to collagen integrity. Therefore in this study, all maize-derived rCI $\alpha 1$ samples in acidic solutions were not boiled prior to Western blot analysis to avoid collagen degradation.

It is interesting to note that both maize- and Pichiaderived non-hydroxylated $\mathrm{rCI} \alpha 1$ were completely digested by pepsin at $10^{\circ} \mathrm{C}$ after the temperature treatment of samples at $4^{\circ} \mathrm{C}$ in our study (Figure $5 \mathrm{~A}$ ). This result is different from what was reported in barley [7] and maize [11], in which plant- and Pichia-derived rCI $\alpha 1$ were still detectable after the heat treatment of $26-27^{\circ} \mathrm{C}$. This could be attributed to the different pepsin treatment protocols used in the experiments. For example, the pepsin experiments reported by Zhang et al[11] were conducted under $\mathrm{pH} 7$, with a 15 minutes heat treatment followed by $150 \mu \mathrm{g} / \mathrm{mL}$ pepsin digestion at $4^{\circ}$ C for 16-18 hr. Ritala et al[7] conducted the heat treatment for $6 \mathrm{~min}$ before subjecting the samples to 150 
$\mu \mathrm{g} / \mathrm{mL}$ pepsin digestion at $10^{\circ} \mathrm{C}$ for 30 min under an acidic condition. Our conditions were similar to Ritala et al except that we used $200 \mu \mathrm{g} / \mathrm{mL}$ pepsin for $15 \mathrm{~min}$ under $\mathrm{pH}$ 1.7. Because pepsin functions best in acidic environment, our pepsin digestion under low $\mathrm{pH}$ is likely leading to the degradation of non-hydroxylated rCI 1 even at $4^{\circ} \mathrm{C}$. Another explanation could be the quantity of the collagen substrate used in different experiments. We estimated that approximately 50-100 $\mathrm{ng} /$ reaction of unpurified $\mathrm{rCI} \alpha 1$ from CGB seeds were subjected to pepsin digestion in our study. However, Zhang et al used about 600 - 700 ng purified $\mathrm{rCI} \alpha 1$ per reaction in their study [11]. The quantity of collagen for pepsin digestion in Ritala et al[7] was not specified.

We have demonstrated for the first time that mammalian-like hydroxylation of human $\mathrm{rCI} \alpha 1$ can be achieved in transgenic maize co-expressed with a human $\mathrm{rP} 4 \mathrm{H}$. The Hyp content in maize-derived hydroxylated $\mathrm{rCI} \alpha 1$ is comparable to that of the native human version, leading to a similar thermal stability of the product. The current expression levels of collagen reported here are too low for large scale production, as desired accumulation level of recombinant proteins for commercial production is estimated between 250 to $1000 \mathrm{mg} / \mathrm{kg}$ grain $[34,35]$. Further improvement of recombinant protein production in plants can be achieved by optimization of gene expression including using more effective regulatory elements and protein targeting/retention sequences, as well as using conventional breeding program to select high expression lines over generations $[34,36]$.

\section{Conclusions}

In this study we have shown that properly hydroxylated recombinant human collagen I alpha 1 (rCI $\alpha 1$ ) can be produced in maize seed. By co-expressing recombinant human prolyl 4-hydroxylases (rP4Hs), we have successfully produced $\mathrm{rCI} \alpha 1$ containing Hyp residue levels that are comparable to native human CI $\alpha 1$. The increased Hyp content is associated with increased thermal stability in maize-derived $\mathrm{rCI} \alpha 1$. Application of highresolution mass spectrometry (HRMS) allowed us to measure hydroxylated prolines at specific amino acid positions in different samples. Our findings indicate that maize seed can be used as a system to produce recombinant proteins requiring mammalian-like posttranslational modifications.

\section{Methods}

\section{Vector construction}

Human collagen type I $\alpha 1$ (CI $\alpha 1)$ coding sequence together with its original $\mathrm{N}$ - and C-telopeptides sequences (UniProtKB/Swiss-Prot: P02452) were optimized by Aptagen LLC (Jacobus, PA) for expression in maize. The optimized CI $\alpha 1$ sequence was fused with a 29 amino acids bacteriophage foldon peptide sequence [23] at the C-terminus to produce a protein with 1086 amino acids. Two constructs (Figure 1 ) were made to produce either recombinant $\mathrm{CI} \alpha 1$ ( $\mathrm{rCI} \alpha 1$ ) only (CGB), or both $\mathrm{rCI} \alpha 1$ and recombinant human prolyl-4-hydroxylase (rP4H, CGD). The $\mathrm{rCI} \alpha 1$ gene was regulated by a maize embryo-specific promoter, globulin-1 [18], with a 3'-terminator from potato protease inhibitor II (pin II) gene. Genes encoding two subunits of $\mathrm{rP} 4 \mathrm{H}(\mathrm{rP} 4 \mathrm{H} \alpha$ and $\mathrm{rP} 4 \mathrm{H} \beta$ ) were regulated by a maize constitutive promoter (ubiquitin promoter) and the potato pin II gene terminator. All three gene coding sequences ( $\mathrm{rCl} \alpha 1, \mathrm{rP} 4 \mathrm{H} \alpha$, and $\mathrm{rP} 4 \mathrm{H} \beta$ ) in the two constructs were translationally fused with a barley alpha amylase signal sequence (BAASS, [19]) at the 5' end. The phosphinothricin acetyl transferase (bar) gene driven by the cauliflower mosaic virus (CaMV) 35S promoter was adopted in both constructs to be a marker for the transgenic callus selection. It confers resistance to the herbicide glufosinate ammonium (bialaphos) [37-39].

\section{Production of transgenic plants}

Constructs CGB and CGD were introduced into immature embryos of Hi II maize genotype [40] via an Agrobacterium-based transformation system [41]. Briefly, maize immature embryos were infected by Agrobacterium strain EHA101 [42] containing the above described vectors and selected on $3 \mathrm{mg} / \mathrm{L}$ bialaphos. Regeneration of transgenic plants from the callus was as previously described [20]. Seedlings were transplanted into soil in the greenhouse and allowed to flower and produce seed through hand-pollinations. Seed increases for multiple events from CGB and CGD were conducted in greenhouse and nursery trials. $T_{2}$ transgenic maize seeds were used for further analysis in this study.

\section{PCR analysis of transgenic plants}

Total genomic DNA was isolated by Cetyl Trimethyl Ammonium Bromide (CTAB) method [43] from maize leaf or seed. The presence of transgenes $\mathrm{rCI} \alpha 1, \mathrm{rP} 4 \mathrm{H} \alpha$ and $\mathrm{rP} 4 \mathrm{H} \beta$ were detected by polymerase chain reaction (PCR). A typical PCR reaction consists $100 \mathrm{ng}$ of genomic DNA, $0.8 \mathrm{mM}$ of dNTPs, $2 \mathrm{mM}$ of $\mathrm{MgCl}_{2}$, Taq DNA polymerase buffer and $0.5 \mathrm{U}$ Taq DNA polymerase (Bioline USA Inc, Taunton, MA) in a final volume of $25 \mu \mathrm{L}$. PCR was performed at the following condition for 35 cycles: 30 s denaturation at $94^{\circ} \mathrm{C}, 30 \mathrm{~s}$ annealing at $60^{\circ} \mathrm{C}$, and $45 \mathrm{~s}$ extension at $70^{\circ} \mathrm{C}$. Primers for amplifying rCI $\alpha 1$ are $\mathrm{x} 7-05$ (5'-ACCAGATGGGCCGCTCTCACCTTT-3') and x7-06 (5'-TTCCCTGGTGCCGTTGGAGCTA-3'); for rP4H $\alpha$ are x7-17 (5'-ATCTCGGCGTCGCTGATGAT-3') and x718 (5'-GTGGTCCGAGCTGGAGAACC-3'); and for 
rP4H 3 are x7-13 (5'-ATGAAGAACACCTCCTCC CTCTG-3') and x7-14 (5'-TCACAGCTCGTCCTTCACGG-3'). PCR products were analyzed in $1 \%$ agarose gel. The expected sizes of PCR products are $1308 \mathrm{bp}$ (rCI $\alpha$ 1), 745 bp $(\mathrm{rP} 4 \mathrm{H} \alpha)$ and 1531 bp (rP4H $\beta)$, respectively. Gel was stained by ethidium bromide $(0.5 \mu \mathrm{g} / \mathrm{ml})$ for $20 \mathrm{~min}$. The products size was determined by $1 \mathrm{~kb}$ DNA Ladder (cat \# N3232S, New England Biolabs).

\section{Protein extraction}

Total soluble protein (TSP) from maize seeds was extracted using an acidic buffer described by [11] for collagen preparation. Maize seeds were ground in a coffee grinder (Mr. Coffee) for $1 \mathrm{~min}$. For rCI $\alpha 1$ extraction, extraction buffer (0.1 M phosphoric acid, $0.15 \mathrm{M}$ sodium chloride, $\mathrm{pH}$ 1.7) was added in to the seed powder at the ratio of $1: 10(\mathrm{w} / \mathrm{v})$. For $\mathrm{rP} 4 \mathrm{H}$ extraction, extraction buffer [ $25 \mathrm{mM}$ sodium phosphate $(\mathrm{pH} 6.6)$, $100 \mathrm{mM}$ sodium chloride, $0.1 \%$ Triton X-100 (v/v), 1 $\mathrm{mM}$ EDTA, $10 \mu \mathrm{g} / \mathrm{mL}$ leupeptin, and $0.1 \mathrm{mM}$ serine protease inhibitor Perfabloc SC (Fluka)] was added into the seed powder at the ratio of 1:10 (w/v). The mixture was incubated in a shaker incubator $\left(250 \mathrm{rpm}, 37^{\circ} \mathrm{C}\right)$ for 0.5 hour for $\mathrm{rCI} \alpha 1$ and one hour for $\mathrm{rP} 4 \mathrm{H}$. The mixtures were then centrifuged at $13,000 \mathrm{rpm}$ for $10 \mathrm{~min}$ at room temperature in a bench top centrifuge. The supernatants were transferred to clean tubes for further analysis. Some protein samples were concentrated by Amicon Ultra-15 Centrifugal Filter Unit with Ultracel30 membrane (cat \# UFC903008, Millipore) followed the product instruction. In short, $15 \mathrm{~mL}$ of total seed protein extraction was loaded into the filter device, centrifuged at $3000 \times \mathrm{g}$ for approximately $2-3$ hours at $4^{\circ} \mathrm{C}$. Concentrated samples were recovered by withdrawing with a pipettor. The concentration level was measured by the volume and could be adjusted by the control of the centrifugation time.

\section{ELISA}

A competitive ELISA procedure developed by FibroGen and described by Zhang et al. [29] was used with minor modifications. Briefly, ELISA plates (cat \# 3590, Corning) were coated overnight at $4^{\circ} \mathrm{C}$ with $5 \mathrm{ng}$ per well of heat-denatured $\left(65 \pm 5^{\circ} \mathrm{C}\right.$ for 30 minutes) non-hydroxylated rCI $\alpha 1$ from Pichia pastoris (FE301,[7]) with phosphate buffer saline (PBS, cat \# 21-040-CV, Mediatech). After washing with washing buffer (10 mM PBS, 0.05\% Tween 20, pH 7.0), the plates were blocked with $2 \%$ dry milk in $100 \mathrm{mM}$ PBS for 1 hour at room temperature. After $3 \times$ washings with washing buffer, heat-denatured samples and standard (FE301) in assay buffer $(100 \mathrm{mM}$ PBS, $0.05 \%$ Tween 20, 1\% dry milk, pH 7.0) were added to the plates. The primary antibody, rabbit polyclonal anti-25 kDa CI 1 (CA725, FibroGen), was added immediately at a 1:4000 dilution in the assay buffer. After 1 hour incubation at room temperature, plates were washed $3 \times$ with washing buffer. The goat-antirabbit IgG $(\mathrm{H}+\mathrm{L})$ HRP conjugate (cat \# 81-6120, Zymed) was added at a 1:5000 dilution in the assay buffer followed by incubation at room temperature for 1 hour. After $3 \times$ washings with washing buffer, $100 \mu \mathrm{L} /$ well of Sure Blue TMB substrate solution (cat \# 52-0001, Kirkegarrd \& Perry Laboratories) were added. The plated were then read at $620 \mathrm{~nm}$ on a microplate reader (KC4, Biotek) after incubation at room temperature for 30 minutes.

\section{Western blotting}

Forty microliters of protein extract from maize seed were mixed with $8 \mu \mathrm{L}$ of Laemmli sample buffer (cat \# 161-0737, Bio-Rad) and then loaded onto a 4-15\% polyacrylamide SDS-PAGE gel (cat \# 161-1158, Bio-Rad). To avoid protein degradation in the combination of acidic $\mathrm{pH}$ and high temperature (X. Xu, unpublished), the step of sample boiling prior to loading was omitted. The proteins separated on the gel were transferred to a $0.45 \mu \mathrm{m}$ nitrocellulose membrane using Bio-Rad Semidry Transblotting apparatus according to the manufacturer's instructions. Membranes were incubated in blocking buffer (138 mM sodium chloride, $2.7 \mathrm{mM}$ potassium chloride, pH 7.4, 0.1\% Tween-20, 5\% dry milk powder) for 1 hour at room temperature on a rotary shaker. The membrane was then incubated for 1 hour in blocking buffer with 1:1000 dilution of anti-foldon antibody (rabbit anti-sera with $0.01 \%$ sodium azide) for the $\mathrm{rCI} \alpha 1$, and with 1:1000 dilution of anti-P4H $\beta$ antibody (cat \# 63-164, ICN Biomedicals) for the $\mathrm{rP} 4 \mathrm{H} \beta$. After washing with washing buffer (138 $\mathrm{mM}$ sodium chloride, $2.7 \mathrm{mM}$ potassium chloride, $\mathrm{pH} 7.4,0.05 \%$ Tween-20) 4 times (5 min each wash), the membrane was then incubated for 1 hour in blocking buffer with 1:5000 dilution of HRPGoat anti-rabbit IgG $(\mathrm{H}+\mathrm{L})$ secondary antibody (cat \# 62-6120, Zymed) for the rCI $\alpha 1$, and with 1:5000 dilution of HRP-Goat anti-mouse IgG $(\mathrm{H}+\mathrm{L})$ secondary antibody (cat \# 62-6520, Zymed) for the P4H $\beta$. After washing the membrane with washing buffer $4 \times 5 \mathrm{~min}$, the excess buffer was then drained off and the membrane transferred into a clean container. Bands appeared after incubation with horseradish peroxidase substrate, 3,3', 5,5'tetramethylbenzidine (cat \# T0565, Sigma) within 10 minutes.

\section{High-resolution mass spectrometry (HRMS) analysis}

To prepare maize-derived $\mathrm{rCI} \alpha 1,10 \mu \mathrm{g}$ of total soluble proteins extracted from seeds was separated on the 4$15 \%$ polyacrylamide SDS-PAGE gel followed by Bio-Safe Coomassie Stain (cat \# 161-0786, Bio-Rad). For purified collagen control samples, three micrograms of each of 
Pichia-derived non-hydroxylated collagen (FE291), Pichia-derived hydroxylated collagen (FE285), and human collagen (cat \# 234138, CalBiochem Inc.) were loaded on the gel. After electrophoresis, collagen bands were excised from the gels and sent to the Proteomics \& Mass Spectrometry Facility at Donald Danforth Plant Science Center, St. Louis, MO for analysis. The samples were automatically digested with trypsin performed by MultiProbe II protein digester (PerkinElmer) in a temperature-controlled enclosed environment. After digestion, samples were run by LC-MS/MS on the Linear Ion Trap Orbitrap (LTQ-Velos Orbitrap, ThermoFisher Scientific). For post-translational modification analysis, the numbers of Hyp and Pro from each sample were counted and compared.

\section{Thermal stability analysis}

The melting temperature $(\mathrm{Tm})$ of CI 1 samples was determined by pepsin digestion after heat treatment [23]. Twenty-five microliters of total soluble protein extracted from CGB and CGD maize seed was subjected to heat treatment in a Thermocycler machine (Biometra $\mathrm{GmbH}$, Germany) at $4^{\circ} \mathrm{C}$, or at temperatures ranged from $29^{\circ} \mathrm{C}$ to $38.6^{\circ} \mathrm{C}$ for $6 \mathrm{~min}$. For positive controls, $1.4 \mu \mathrm{g}$ of Pichiaderived rCI 1 in hydroxylated (FE285) and non-hydroxylated (FE291) forms, and human collagen were also treated. After heat treatment, all protein samples were then incubated at $10^{\circ} \mathrm{C}$ with or without pepsin $(0.2 \mathrm{mg} / \mathrm{mL}$ final concentration, cat \# P6887, Sigma) for 15 min. Digestion results were analyzed by western blotting using anti foldon and anti $25 \mathrm{kDa}$ collagen antibodies.

\footnotetext{
Acknowledgements and Funding

The authors thank Cheng Zhang, Charles E. Glatz, Matt Aspelund and Christopher M Setina for helpful discussions and sharing immune blot materials and methods, Susana Martin Ortigosa for assisting in image preparation, Jessica Zimmer and Angela Nguyen for technical assistances. We also thank Michael Horn, Carol Drees and other former ProdiGene employees for maize transformation, greenhouse care and field operations, and Sheri Almeda and James Polarek for their support to this program at FibroGen. Partial financial support for this project was provided by the United States Department of Agriculture (USDA special grant IOW05082) and the Biopharmaceutical/Bioindustrial Initiative of the Plant Sciences Institute at lowa State University.
}

\section{Author details}

${ }^{1}$ Interdepartmental Plant Biology Major, lowa State University, Ames, IA 50011-1010, USA. ²Department of Agronomy, lowa State University, Ames, IA 50011-1010, USA. ${ }^{3}$ Formerly of ProdiGene, Inc., USA. ${ }^{4}$ Current address: Texas Engineering Experiment Station, Food Protein R\&D Center, College Station, Texas 77843, USA. ${ }^{5}$ Current address: University of South Florida, Tampa, FL 33620, USA. ${ }^{6}$ Applied Biotechnology Institute, San Luis Obispo, CA 93407 USA. ${ }^{7}$ FibroGen Inc., 409 Illinois Street, San Francisco, CA 94158, USA. ${ }^{8}$ Current address: Richmond Chemical Corporation, 2010 Midwest Rd. Oakbrook, IL 60523, USA.

\section{Authors' contributions}

$X X$ carried out all the molecular analysis on $T_{2}$ transgenic seeds and drafted the manuscript. QG assisted with XX for protein analysis. RC made constructs for maize transformation and conducted the molecular analysis. KP carried out the biochemical analysis in maize plants. JH, JB and KW conceived the study and review the paper. KW designed the experiment and edited the paper. All authors read and approved this final manuscript.

Received: 11 March 2011 Accepted: 24 June 2011

Published: 24 June 2011

\section{References}

1. Lee $\mathrm{CH}$, Singla A, Lee Y: Biomedical applications of collagen. International Journal of Pharmaceutics 2001, 221:1-22.

2. Olsen D, Yang CL, Bodo M, Chang R, Leigh S, Baez J, Carmichael D, Perala M, Hamalainen ER, Jarvinen M, et al: Recombinant collagen and gelatin for drug delivery. Advanced Drug Delivery Reviews 2003, 55:1547-1567.

3. Vanderrest M, Garrone R: Collagen Family of Proteins. FASEB Journal 1991, 5:2814-2823

4. Geddis AE, Prockop DJ: Expression of human COL1A1 gene in stably transfected HT1080 cells: the production of a thermostable homotrimer of type I collagen in a recombinant system. Matrix 1993, 13:399-405.

5. Myllyharju J, Lamberg A, Notbohm H, Fietzek PP, Pihlajaniemi T, Kivirikko Kl: Expression of wild-type and modified pro alpha chains of human type I procollagen in insect cells leads to the formation of stable [alpha 1(I)](2) alpha $2(\mathrm{I})$ collagen heterotrimers and [alpha 1(I)](3) homotrimers but not [alpha 2(I)](3) homotrimers. Journal of Biological Chemistry 1997, 272:21824-21830.

6. Vuorela A, Myllyharju J, Nissi R, Pihlajaniemi T, Kivirikko Kl: Assembly of human prolyl 4-hydroxylase and type III collagen in the yeast Pichia pastoris: formation of a stable enzyme tetramer requires coexpression with collagen and assembly of a stable collagen requires coexpression with prolyl 4-hydroxylase. The EMBO Journal 1997, 16:6702-6712.

7. Ritala A, Wahlstrom EH, Holkeri H, Hafren A, Makelainen K, Baez J, Makinen K, Nuutila AM: Production of a recombinant industrial protein using barley cell cultures. Protein Expression and Purification 2008, 59:274-281.

8. Ma JKC, Drake PMW, Christou P: The production of recombinant pharmaceutical proteins in plants. Nature Reviews Genetics 2003, 4:794-805.

9. Menkhaus TJ, Bai Y, Zhang CM, Nikolov ZL, Glatz CE: Considerations for the recovery of recombinant proteins from plants. Biotechnology Progress 2004, 20:1001-1014.

10. Ruggiero F, Exposito JY, Bournat P, Gruber V, Perret S, Comte J, Olagnier B, Garrone R, Theisen M: Triple helix assembly and processing of human collagen produced in transgenic tobacco plants. FEBS Letters 2000, 469:132-136.

11. Zhang C, Baez J, Pappu KM, Glatz CE: Purification and characterization of a transgenic corn grain-derived recombinant collagen type I alpha 1. Biotechnology Progress 2009, 25:1660-1668.

12. Zhang C, Glatz CE, Fox SR, Johnson LA: Fractionation of transgenic corn seed by dry and wet milling to recover recombinant collagen-related proteins. Biotechnology Progress 2009, 25:1396-1401.

13. Eskelin K, Ritala A, Suntio T, Blumer S, Holkeri H, Wahlstrom EH, Baez J, Makinen K, Maria NA: Production of a recombinant full-length collagen type I alpha-1 and of a 45-kDa collagen type I alpha-1 fragment in barley seeds. Plant Biotechnology Journal 2009, 7:657-672.

14. Myllyharju J: Prolyl 4-hydroxylases, the key enzymes of collagen biosynthesis. Matrix Biology 2003, 22:15-24.

15. Kotch FW, Guzei IA, Raines RT: Stabilization of the collagen triple helix by O-methylation of hydroxyproline residues. Journal of the American Chemical Society 2008, 130:2952-2953.

16. Merle C, Perret S, Lacour T, Jonval V, Hudaverdian S, Garrone R, Ruggiero F, Theisen M: Hydroxylated human homotrimeric collagen I in Agrobacterium tumefaciens-mediated transient expression and in transgenic tobacco plant. FEBS Letters 2002, 515:114-118.

17. Stein H, Wilensky M, Tsafrir $Y$, Rosenthal M, Amir R, Avraham T, Ofir K, Dgany O, Yayon A, Shoseyov O: Production of bioactive, posttranslationally modified, heterotrimeric, human recombinant type-I collagen in transgenic tobacco. Biomacromolecules 2009, 10:2640-2645.

18. Belanger FC, Kriz AL: Molecular-Basis for Allelic Polymorphism of the Maize Globulin-1 Gene. Genetics 1991, 129:863-872.

19. Rogers JC: Two barley alpha-amylase gene families are regulated differently in aleurone cells. The Journal of biological chemistry 1985, 260:3731. 
20. Hood EE, Bailey MR, Beifuss K, Magallanes-Lundback M, Horn ME, Callaway E, Drees C, Delaney DE, Clough R, Howard JA: Criteria for highlevel expression of a fungal laccase gene in transgenic maize. Plant Biotechnology Journal 2003, 1:129-140.

21. Hood EE, Love R, Lane J, Bray J, Clough R, Pappu K, Drees C, Hood KR Yoon S, Ahmad A, et al: Subcellular targeting is a key condition for highlevel accumulation of cellulase protein in transgenic maize seed. Plant Biotechnology Journal 2007, 5:709-719.

22. Lamphear BJ, Barker DK, Brooks CA, Delaney DE, Lane JR, Beifuss K, Love R, Thompson K, Mayor J, Clough R, et al: Expression of the sweet protein brazzein in maize for production of a new commercial sweetener. Plant Biotechnology Journal 2005, 3:103-114.

23. Pakkanen O, Hamalainen ER, Kivirikko KI, Myllyharju J: Assembly of stable human type I and III collagen molecules from hydroxylated recombinant chains in the yeast Pichia pastoris - Effect of an engineered C-terminal oligomerization domain foldon. Journal of Biological Chemistry 2003, 278:32478-32483.

24. Christensen AH, Sharrock RA, Quail PH: Maize polyubiquitin genes structure, thermal perturbation of expression and transcript splicing, and promoter activity following transfer to protoplasts by electroporation. Plant Molecular Biology 1992, 18:675-689.

25. Witcher DR, Hood EE, Peterson D, Bailey M, Bond D, Kusnadi A, Evangelista R, Nikolov Z, Wooge C, Mehigh R, et al: Commercial production of beta-glucuronidase (GUS): a model system for the production of proteins in plants. Molecular Breeding 1998, 4:301-312.

26. Hutton JJ Jr, Kaplan A, Udenfriend S: Conversion of the amino acid sequence gly-pro-pro in protein to gly-pro-hyp by collagen proline hydroxylase. Archives of Biochemistry and Biophysics 1967, 121:384-391.

27. Perret S, Merle C, Bernocco S, Berland P, Garrone R, Hulmes DJ, Theisen M, Ruggiero F: Unhydroxylated triple helical collagen I produced in transgenic plants provides new clues on the role of hydroxyproline in collagen folding and fibril formation. Journal of Biological Chemistry 2001, 276:43693-43698.

28. Miller EJ, Gay S: Collagen: an overview. Methods Enzymology 1982, 82(Pt A):3-32.

29. Zhang C, Baez J, Glatz CE: Purification and characterization of a 44-kDa recombinant collagen I alpha 1 fragment from corn grain. Journal of Agricultural and Food Chemistry 2009, 57:880-887.

30. Gorres KL, Raines RT: Prolyl 4-hydroxylase. Critical Reviews in Biochemistry and Molecular Biology 2010, 45:106-124.

31. Kivirikko Kl, Myllylä R, Pihlajaniemi T: Hydroxylation of proline and lysine residues in collagens and other animal and plant proteins. In Posttranslational modifications of proteins. Edited by: Harding JJC, M. James C. Boca Raton: CRC Press; 1992:1-52.

32. Shoulders MD, Raines RT: Collagen Structure and Stability. Annual Review of Biochemistry 2009, 78:929-958.

33. Yang C, Hillas PJ, Baez JA, Nokelainen M, Balan J, Tang J, Spiro R, Polarek JW: The application of recombinant human collagen in tissue engineering. BioDrugs 2004, 18:103-119.

34. Hood EE, Witcher DR, Maddock S, Meyer T, Baszczynski C, Bailey M, Flynn P, Register J, Marshall L, Bond D, et al: Commercial production of avidin from transgenic maize: characterization of transformant, production, processing, extraction and purification. Molecular Breeding 1997, 3:291-306.

35. Nandi S, Yalda D, Lu S, Nikolov Z, Misaki R, Fujiyama K, Huang N: Process development and economic evaluation of recombinant human lactoferrin expressed in rice grain. Transgenic Research 2005, 14:237-249.

36. Chikwamba R, McMurray J, Shou HX, Frame B, Pegg SE, Scott P, Mason H, Wang K: Expression of a synthetic E-coli heat-labile enterotoxin B subunit (LT-B) in maize. Molecular Breeding 2002, 10:253-265.

37. Anzai $\mathrm{H}$ : Transgenic tobacco resistant to a bacterial disease by the detoxification of a pathogenic toxin. Molecular \& general genetics 1989 219:492.

38. Gordon-Kamm WJ: Transformation of maize cells and regeneration of fertile transgenic plants. The Plant Cell 1990, 2:603.

39. Uchimiya $\mathrm{H}$ : Bialaphos treatment of transgenic rice plants expressing a bar gene prevents infection by the sheath blight pathogen (Rhizoctonia solani). Nature Biotechnology 1993, 11:835.

40. Armstrong CL, Green CE, Phillips RL: Development and availability of germplasm with high Type II culture formation response. Maize Genet Coop Newsl 1991, 65:92-93.
41. Ishida Y, Saito H, Ohta S, Hiei Y, Komari T, Kumashiro T: High efficiency transformation of maize (Zea mays $\mathrm{L}$ ) mediated by Agrobacterium tumefaciens. Nature Biotechnology 1996, 14:745-750.

42. Hood EE, Helmer GL, Fraley RT, Chilton MD: The hypervirulence of Agrobacterium tumefaciens A281 is encoded in a region of pTiBo542 outside of transfer DNA. Journal of Bacteriology 1986, 168:1291-1301.

43. Murray MG, Thompson WF: Rapid isolation of high molecular-weight plant DNA. Nucleic Acids Research 1980, 8:4321-4325.

doi:10.1186/1472-6750-11-69

Cite this article as: Xu et al:: Hydroxylation of recombinant human collagen type I alpha 1 in transgenic maize co-expressed with a recombinant human prolyl 4-hydroxylase. BMC Biotechnology 2011 11:69.

\section{Submit your next manuscript to BioMed Central and take full advantage of:}

- Convenient online submission

- Thorough peer review

- No space constraints or color figure charges

- Immediate publication on acceptance

- Inclusion in PubMed, CAS, Scopus and Google Scholar

- Research which is freely available for redistribution

Submit your manuscript at www.biomedcentral.com/submit
Biomed Central 